\title{
Clinical and pathological characteristics related to parametrial involvement in clinical early-stage cervical cancer
}

\author{
Gokhan Boyraz, Derman Basaran, Mehmet C. Salman, Nejat Ozgul, Kunter Yuce \\ Department of Obstetrics and Gynecology, Faculty of Medicine, Hacettepe University, Ankara, Turkey
}

\begin{abstract}
Objectives: Since parametrial involvement is believed to be a crucial factor in the management of cervical cancer, our study was designed to investigate the clinical and pathological features which predicted parametrial involvement in patients with clinical early-stage cervical cancer.

Material and methods: The study included patients with clinical early-stage cervical cancer who underwent radical hysterectomy with pelvic and para-aortic lymphadenectomy between December 2001 and August 2014, at the Hacettepe University Hospital. The clinical and pathological characteristics of the affected patients were evaluated, including age, histologic subtype, tumor size, depth of cervical stromal invasion, lympho-vascular space invasion (LVSI), and lymph node metastasis. Univariate and multivariate analyses were performed to reveal factors associated with parametrial involvement.

Results: The study group consisted of 126 patients (mean age: 52.7 years; range: 29-83), including 101 (80.2\%) with squamous, 19 (15.1\%) with adenocarcinoma, and 6 (4.8\%) with adenosquamous histological subtype of cervical cancer. Parametrial involvement and lymph node metastasis were detected in 41 (32.5\%) and 46 (36.5\%) women, respectively. Univariate analysis showed that deep cervical stromal invasion, LVSI, tumor size $>2 \mathrm{~cm}$ and lymph node metastasis were associated with parametrial involvement. Multivariate logistic regression analysis identified the independent risk factors associated with parametrial involvement as LVSI (OR 8.93,95\% CI 1.1-73.5, $\mathrm{p}=0.042)$ and lymph node metastasis (OR 8.8, $95 \% \mathrm{Cl} 1.5-9.3, \mathrm{p}=0.004)$.

Conclusions: LVSI, deep cervical stromal invasion, lymph node metastasis and tumor size are significantly associated with parametrial involvement in patients with clinical early-stage cervical cancer.
\end{abstract}

Key words: cervical cancer, cervical stromal invasion, lympho-vascular space involvement, parametrial involvement

Ginekologia Polska 2016; 87, 6: 417-421

\section{INTRODUCTION}

Cervical cancer is the third most frequent common gynecologic cancer, preceded only by endometrial and ovarian cancer, and a common cause of gynecologic cancer-related death despite the availability of effective screening tools [1]. In contrast to other gynecological cancers, staging of cervical cancer is based on clinical examination according to the International Federation of Gynecology and Obstetrics (FIGO) criteria [2]. Radical hysterectomy and pelvic lymphadenectomy remains the standard treatment option for most patients with clinical early-stage cervical cancer. The advantages of surgical treatment include removal of the primary tumor, shorter treatment time, the possibility to preserve ovarian and sexual function, and to determine the need for adjuvant therapy by histologic examination [3]. In contrast to simple hysterectomy, radical hysterectomy involves removal of the parametrial tissue and is associated with adverse impact on the quality of patient life [4]. Visceral injuries, bleeding, infection and febrile morbidity, fistula formation, sexual dysfunction, bladder and bowel dysfunction are the most common complications of radical hysterectomy and some of these problems may be irreversible [5]. Direct extension and lymphatic dissemination are the most common routes of spread in cervical cancer. There- 
fore, parametrium and lymph nodes are typical metastasis locations and removal of these tissues is vial in cervical cancer treatment [6]. However, most of the complications related to radical hysterectomy are also associated with parametrial resection due to autonomic nerve damage [7]. In selected patients with early stage cervical cancer, less radical surgical procedures without parametrial resection (e.g. simple hysterectomy or conization) may be associated with fewer surgical complications. The assessment of parametrial involvement must be done before omission of parametrial resection in candidates for less radical surgery [8].

\section{OBJECTIVES}

Since parametrial involvement is believed to be a crucial factor in the management of cervical cancer, our study was designed to investigate the clinical and pathological features which predicted parametrial involvement in patients with clinical early-stage cervical cancer.

\section{MATERIAL AND METHODS}

The study included patients with clinical early-stage cervical cancer who underwent radical hysterectomy and pelvic and para-aortic lymphadenectomy between December 2001 and August 2014 at the Hacettepe University Hospital. Piver-Rutledge type III radical hysterectomy was performed, with the removal of uterus, cervix, upper third of the vagina and parametrial resection until the pelvic sidewall. Lymphadenectomy consisted of systematic pelvic and para-aortic lymph node dissection up to the level of inferior mesenteric artery. The patients were staged by clinical examination according to the 2009 FIGO criteria. A total of 126 consecutive women were analyzed retrospectively. The clinical and pathological characteristics of the patients were evaluated, including patient age, histologic subtype, tumor size, depth of cervical stromal invasion, lympho-vascular space invasion (LVSI), and lymph node metastasis. Statistical analyses were performed using SPSS software version 17.0 statistical package. Cross tabulations were analyzed using $x^{2}$ or Fisher's exact test. Non-parametric continuous variables were analyzed using the Mann-Whitney $U$ test. The $p$-value of $<0.05$ was considered as statistically significant.

As this study represents a retrospective chart review, permission of the Local Ethics Committee was not sought. However, all patients signed an informed consent which allowed our institution to use their clinical data.

\section{RESULTS}

The clinical and pathological characteristics of the cases are summarized in Table 1. The study group consisted of 126 patients (mean age: 52.7 years; range: $29-83$ ), including 69 (54.8\%) postmenopausal and 57 (45.2\%) premenopausal

\begin{tabular}{|c|c|}
\hline Variable & Patients $(n=126)$ \\
\hline Mean age (years) & 52.7 (ranging 29-83) \\
\hline $\begin{array}{l}\text { Histology } \\
\text { Squamous carcinoma } \\
\text { Adenocarcinoma } \\
\text { Adenosquamous carcinoma }\end{array}$ & $\begin{array}{l}101(80.2 \%) \\
19(15.1 \%) \\
6(4.8 \%)\end{array}$ \\
\hline $\begin{array}{l}\text { Tumor size }[\mathrm{cm}] \\
2 \text { or less } \\
\text { More than } 2\end{array}$ & $\begin{array}{l}20(15.9 \%) \\
106(84.1 \%)\end{array}$ \\
\hline $\begin{array}{l}\text { Depth of cervical stromal invasion } \\
\quad<50 \% \text { of full thickness } \\
\geq 50 \% \text { of full thickness }\end{array}$ & $\begin{array}{l}19(15.1 \%) \\
107(84.9 \%)\end{array}$ \\
\hline $\begin{array}{l}\text { Lymphovascular space invasion } \\
\text { Yes } \\
\text { No }\end{array}$ & $\begin{array}{l}96(76.2 \%) \\
30(23.8 \%)\end{array}$ \\
\hline $\begin{array}{l}\text { Lymph node metastasis } \\
\text { Yes } \\
\text { Only Pelvic } \\
\text { Only Para-aortic } \\
\text { Pelvic + Para-aortic } \\
\text { No }\end{array}$ & $\begin{array}{l}46(36.5 \%) \\
36(28.5 \%) \\
2(1.5 \%) \\
8(6.34 \%) \\
80(63.5 \%)\end{array}$ \\
\hline $\begin{array}{l}\text { Parametrial involvement } \\
\text { Yes } \\
\text { No }\end{array}$ & $\begin{array}{l}41(32.53 \%) \\
85(67.47 \%)\end{array}$ \\
\hline $\begin{array}{l}\text { Surgical margin } \\
\text { Positive } \\
\text { Negative }\end{array}$ & $\begin{array}{l}16(12.7 \%) \\
110(87.3 \%)\end{array}$ \\
\hline
\end{tabular}

women. Of the 126 patients, 101 (80.2\%) had squamous, 19 (15.1\%) had adenocarcinoma, and 6 (4.8\%) had adenosquamous histological subtype of cervical cancer. Parametrial involvement was detected in 41 (32.5\%) subjects. Of the 41 cases with parametrial involvement, 22 (17.5\%) had microscopic and 19 (15.1\%) had macroscopic involvement, based on the pathology report. While 39 cases had direct parametrial spread, lymphatic parametrial spread was detected in 5 cases.

Of the factors analyzed for correlation with parametrial involvement in clinical early-stage cervical cancer, tumor size, lympho-vascular space invasion, deep cervical invasion, and lymph node metastasis were found to be significant predictors of parametrial involvement (Table 2). While only 1 of the patients with $\leq 2 \mathrm{~cm}$ tumor size had parametrial involvement, 40 (37.73\%) of the 106 patients with $>2 \mathrm{~cm}$ tumor size had parametrial involvement.

Deep cervical stromal invasion ( $\geq 50 \%$ of full thickness) was detected in 107 (84.9\%) subjects. While parametrial involvement was detected in 41 (38.31\%) of the 107 patients with deep cervical stromal invasion, none of the patients with superficial cervical stromal invasion had parametrial involvement $(p=0.001)$.

LVSI was detected in 96 (76.2\%) patients and the remaining 30 patients did not have LVSI. Of the 30 patients without 


\begin{tabular}{|c|c|c|c|}
\hline Variable & Parametrial involvement $(n=41)$ & No parametrial involvement $(n=85)$ & p \\
\hline Mean age & 55.0 & 51.7 & 0.772 \\
\hline $\begin{array}{l}\text { Histologic type } \\
\text { Squamous } \\
\text { Adenocarcinoma } \\
\text { Adenosquamous }\end{array}$ & $\begin{array}{c}34(82.9 \%) \\
4(9.7 \%) \\
3(7.31 \%)\end{array}$ & $\begin{array}{l}67(78.8 \%) \\
15(17.6 \%) \\
3(3.52 \%)\end{array}$ & 0.362 \\
\hline $\begin{array}{l}\text { Tumor size } \\
2 \mathrm{~cm} \text { or less } \\
\text { More than } 2 \mathrm{~cm}\end{array}$ & $\begin{array}{c}1(5 \%) \\
40(37.7 \%)\end{array}$ & $\begin{array}{c}19(95 \%) \\
66(62.3 \%)\end{array}$ & 0.04 \\
\hline $\begin{array}{l}\text { Depth of cervical stromal invasion } \\
\quad<50 \% \\
\geq 50 \%\end{array}$ & $\begin{array}{c}0(0 \%) \\
41(38.7 \%)\end{array}$ & $\begin{array}{l}19(100 \%) \\
66(61.3 \%)\end{array}$ & 0.001 \\
\hline $\begin{array}{l}\text { LVSI } \\
\text { Positive } \\
\text { Negative }\end{array}$ & $\begin{array}{c}40 \text { (41.7\%) } \\
1(3.3 \%)\end{array}$ & $\begin{array}{l}56(58.3 \%) \\
29(96.7 \%)\end{array}$ & $<0.001$ \\
\hline $\begin{array}{l}\text { Lymph node metastasis } \\
\text { Yes } \\
\text { No }\end{array}$ & $\begin{array}{l}26(56.5 \%) \\
15(18.8 \%)\end{array}$ & $\begin{array}{l}20(43.5 \%) \\
65(81.2 \%)\end{array}$ & $<0.001$ \\
\hline $\begin{array}{l}\text { Vaginal involvement } \\
\text { Yes } \\
\text { No }\end{array}$ & $\begin{array}{l}22(71 \%) \\
19(20 \%)\end{array}$ & $\begin{array}{c}9(29 \%) \\
76(80 \%)\end{array}$ & $<0.001$ \\
\hline
\end{tabular}

LVSI - lymphovascular space invasion

LVSI, only 1 had parametrial involvement. On the other hand, of the 96 patients with LVSI, 40 (41.66\%) had parametrial involvement $(p<0.001)$.

No statistically significant difference between age and parametrial involvement was identified ( $p=0.772$ ). Additionally, there was no statistically significant difference between histologic subtype and parametrial involvement ( $p=0.362$ ). Multivariate logistic regression analysis was performed to identify factors related to parametrial involvement. The examined factors included age, histology, tumor size, depth of cervical stromal invasion, lympho-vascular space invasion, and lymph node metastasis. LVSI (OR 8.93, $95 \% \mathrm{Cl} 1.1-73.5, \mathrm{p}=0.042$ ) and lymph node metastasis (OR $8.8,95 \% \mathrm{Cl} 1.5-9.3, \mathrm{p}=0.004$ ) were the only independent predictors associated with parametrial involvement.

\section{DISCUSSION}

After the diagnosis of cervical cancer, all patients should undergo a clinical staging evaluation to determine the treatment approach. In this way, patients with cervical cancer can be classified as early (stage 1-2A) or locally advanced stage (stage 2B-4A) disease. Whilst clinical early-stage cervical cancer can be treated by radical hysterectomy or concomitant chemoradiation, patients with clinical locally advanced-stage cervical cancer are treated with primary chemoradiation [9]. The most important factor in the treatment of cervical cancer is to avoid using multimodality treatment which consists of chemoradiation and surgery.

Radical surgery for cervical cancer is associated with significant complications including fistula formation, bladder and sexual dysfunction [10]. Therefore, patients with low-risk characteristics for parametrial involvement could be treated with less radical approach such as simple hysterectomy or cervical conization. On the other hand, oncological safety of the less radical procedures have not yet been proven and clinicians should select patients with low-risk features with meticulous effort.

More recent studies estimated the rate of parametrial involvement in patients with clinical early-stage cervical cancer at $4-11 \%[11,12]$. However, the parametrial involvement was detected in 41 (32.5\%) patients in our study. Wright et al., reported an association between tumor histology and parametrial involvement, but such association was not present in our patient cohort [13].

An association between lymph node involvement and parametrial involvement has been reported in the literature. Our findings, as well as the literature reports, suggest that the risk of parametrial involvement is strongly associated with lymphatic involvement. In our study, patients with lymphatic metastasis had significantly higher rates of parametrial involvement as compared to patients with no metastasis $(56.5 \%$ vs. $18.8 \%, \mathrm{p}<0.01)$. Frumovitz et al., found that 15 of the 27 women with parametrial involvement also had positive pelvic lymph nodes, which is consistent with our report [7]. Kodama et al., reported that pelvic lymph node status is the strongest independent predictor of parametrial involvement [14]. Similarly, Puente et al., suggested that pelvic lymph node status is a good predictor of parametrial involvement in node-negative patients in whom less radical surgery could be used [15]. 
In our study, we found that LVSI, deep cervical stromal invasion, lymph node metastasis, and tumor size are significant risk factors for parametrial involvement in patients with clinical early-stage cervical cancer. Likewise, O. Gemer et al., detected similar risk factors for parametrial involvement, including tumor size, depth of invasion, LVSI, and positive lymph nodes [11]. These authors suggested an algorithm for patients with early-stage cervical cancer. According to this algorithm, patients with clinically early-stage cervical cancer underwent magnetic resonance imaging to determine tumor size. If the tumor was $<2 \mathrm{~cm}$ in diameter, large loop electro-excisional procedure or conization were performed to detect LVSI. They found that if LVSI was not documented, the rate of parametrial involvement was $1.8 \%(2 / 112)$. In our study, of the 30 cases with no LVSI, only 1 had parametrial involvement (3.3\%). Additionally, in patients with negative lymph nodes on laparoscopic lymphadectomy or sentinel node procedure, the rate of parametrial involvement was $0 \%(0 / 107)$. However, out of the 80 cases with no lymph node metastasis in our study, 15 patients had parametrial involvement (18.75\%).

Our findings, as well as the literature, suggest that the risk of parametrial involvement in patients with tumor size $<2 \mathrm{~cm}$ and no LVSI is generally low $[7,13,16]$. In our study, out of the 5 patients with tumor $<2 \mathrm{~cm}$ and no LVSI, no cases of parametrial involvement were noted. Likewise, Klat et al., reported 204 patients who underwent radical surgery with SLN biopsy. They found no subjects with parametrial involvement among women with early-stage cervical cancer, with tumor $<20 \mathrm{~mm}$ in diameter and negative sentinel lymph nodes [17]. Our findings are consistent with those of Covens et al., who also detected a correlation between tumor size, LVSI, greater depth of invasion, and positive pelvic lymph nodes with parametrial involvement. On the other hand, Covens et al., and Kodama et al., found a significant association between older age and parametrial involvement, but in our study, we observed no link between age and parametrial involvement $[14,18]$.

Most of the recent studies reported a low rate of parametrial involvement in early-stage cervical cancer patients with certain pathological characteristics. Hence, a more conservative approach may be considered in those women $[6,19,20]$. Pluta et al., evaluated 60 patients with FIGO stage IA 1 and IB1 cervical cancer who had $<2 \mathrm{~cm}$ tumor size and $<50 \%$ cervical stromal invasion. Out of the 60 patients, in 55 patients who had negative sentinel lymph nodes on frozen section, simple hysterectomy and pelvic lymphadenectomy were performed and no recurrences were detected in the median follow-up of 47 months. Therefore, they suggested that simple hysterectomy and pelvic lymphadenectomy may be safely performed in selected early-stage cervical cancer patients with certain pathologic characteristics [21].

\section{CONCLUSIONS}

LVSI, deep cervical stromal invasion, lymph node metastasis, and tumor size are significantly associated with parametrial involvement in patients with clinical early-stage cervical cancer. LVSI and lymph node metastasis were the independent factors associated with parametrial involvement in multivariate logistic regression analysis. LVSI could be detected with meticulous pathologic assessment in the preoperative period. Tumor size, deep cervical stromal involvement, and lymph node status could be detected by magnetic resonance imaging and positron emission tomography/computed tomography. Thus, identification of patients with low risk for parametrial involvement might allow for a more conservative surgical approach. On the other hand, patients with high risk of parametrial invasion could be directed to primary chemoradiation and could be spared the morbidity of a multimodal treatment.

\section{Conflict of interest}

The authors have no conflict of interest to declare.

\section{REFERENCES}

1. Jemal, A, Bray F, Center MM, Ferlay J, Ward E, Forman D. Global cancer statistics. CA Cancer J Clin. 2011, 6, 69-90.

2. Pecorelli S, Zigliani L, Odicino F. Revised FIGO staging for carcinoma of the cervix. Int J Gynaecol Obstet. 2009, 105, 107-108.

3. Abu-Rustum NR, Hoskins WJ. Radical abdominal hysterectomy. Surg Clin North Am. 2001, 81, 815-828.

4. Vistad I, Fossa SD, Dahl AA. A critical review of patient-rated quality of life studies of long-term survivors of cervical cancer. Gynecol Oncol. 2006, 102, 563-572.

5. Brooks RA, Wright JD, Powell MA, Rader JS, Gao F, Mutch DG, Wall LL. Long-term assessment of bladder and bowel dysfunction after radical hysterectomy. Gynecol Oncol. 2009, 114, 75-79.

6. Stegeman M, Louwen $\mathrm{M}$, van der Velden J, [et al.]. The incidence of parametrial tumor involvement in select patients with early cervix cancer is too low to justify parametrectomy. Gynecol Oncol. 2007, 105, 475-480.

7. Frumovitz M, Sun CC, Schmeler KM, [et al.]. Parametrial involvement in radical hysterectomy specimens for women with early-stage cervical cancer. Obstet Gynecol. 2009, 114, 93-99.

8. Chang SJ, Bristow RE, Ryu HS. A model for prediction of parametrial involvement and feasibility of less radical resection of parametrium in patients with FIGO stage IB1 cervical cancer. Gynecol Oncol. 2012, $126,82-86$.

9. Landoni F, Maneo A, Colombo A, [et al.]. Randomised study of radical surgery versus radiotherapy for stage Ib-Ila cervical cancer. Lancet. 1997, 350, 535-540.

10. Trimbos JB, Franchi M, Zanaboni F, Velden Jv, Vergote I. State of the art' of radical hysterectomy; current practice in European oncology centres. Eur J Cancer. 2004, 40, 375-378.

11. Gemer O, Eitan R, Gdalevich M, [et al.]. Can parametrectomy be avoided in early cervical cancer? An algorithm for the identification of patients at low risk for parametrial involvement. Eur J Surg Oncol. 2013, 39, 76-80.

12. Steed H, Capstick V, Schepansky A, Honore L, Hiltz M, Faught W. Early cervical cancer and parametrial involvement: is it significant? Gynecol Oncol. 2006, 103, 53-57.

13. Wright JD, Grigsby PW, Brooks R, [et al.]. Utility of parametrectomy for early stage cervical cancer treated with radical hysterectomy. Cancer. 2007, 110, 1281-1286.

14. Kodama J, Kusumoto $T$, Nakamura K, Seki N, Hongo A, Hiramatsu $Y$. Factors associated with parametrial involvement in stage IB1 cervical cancer and identification of patients suitable for less radical surgery. Gynecol Oncol. 2011, 122, 491-494. 
15. Puente R, Guzman S, Israel E, Poblete MT. Do the pelvic lymph nodes predict the parametrial status in cervical cancer stages IB-IIA? Int J Gynecol Cancer. 2004, 14, 832-840.

16. Kinney WK, Hodge DO, Egorshin EV, Ballard DJ, Podratz KC. Identification of a low-risk subset of patients with stage IB invasive squamous cancer of the cervix possibly suited to less radical surgical treatment. Gynecol Oncol. 1995, 57, 3-6.

17. Klat J, Sevcik L, Simetka O, Graf P, Dvorackova J, Kraft O. What is the risk for parametrial involvement in women with early-stage cervical cancer with tumour $<20 \mathrm{~mm}$ and with negative sentinel lymph nodes? Aust $\mathrm{N}$ Z J Obstet Gynaecol. 2012, 52, 540-544.
18. Covens A, Rosen B, Murphy J, [et al.]. How important is removal of the parametrium at surgery for carcinoma of the cervix? Gynecol Oncol. 2002, 84, 145-149.

19. Schmeler KM, Frumovitz M, Ramirez PT. Conservative management of early stage cervical cancer: is there a role for less radical surgery? Gynecol Oncol. 2011, 120, 321-325.

20. Reade CJ, Eiriksson LR, Covens A. Surgery for early stage cervical cancer: how radical should it be? Gynecol Oncol. 2013, 131, 222-230.

21. Pluta $M$, Rob $L$, Charvat $M$, [et al.]. Less radical surgery than radical hysterectomy in early stage cervical cancer: a pilot study. Gynecol Oncol. $2009,113,181-184$ 